Çukurova Üniversitesi Mühendislik Mimarlık Fakültesi Dergisi, 35(4), ss. 937-947, Aralık 2020

Çukurova University Journal of the Faculty of Engineering and Architecture, 35(4), pp. 937-947, December 2020

\title{
Yüksek Sıcaklığın Doğal Taşların Petrografik, Parlaklık ve Pürüzlülük Özelliklerine Etkisi
}

\author{
Zehra Funda TÜRKMENOĞLU ${ }^{* 1}$, Ali ÖZVAN ${ }^{2}$, Elif ERDEVE ÖZVAN ${ }^{3}$, \\ Mehmet TÜRKMENOĞLU ${ }^{4}$, İsmail AKKAYA ${ }^{5}$, Ogün Ozan VAROL ${ }^{6}$, \\ Mucip TAPAN $^{7}$, Esma KAHRAMAN ${ }^{8}$
}

${ }^{1,4,6}$ Van Yüzüncü Yıl Üniversitesi, Mühendislik Fakültesi, Maden Mühendisliği Bölümü, Van

${ }^{2,3}$ Van Yüzüncü Yıl Üniversitesi, Mühendislik Fakültesi, Jeoloji Mühendisliği Bölümü, Van

${ }^{5}$ Van Yüzüncü Yıl Üniversitesi, Mühendislik Fakültesi, Jeofizik Mühendisliği Bölümü, Van

${ }^{7}$ Van Yüzüncü Yll Üniversitesi, Mühendislik Fakültesi, İnşaat Mühendisliği Bölümü, Van

${ }^{8}$ Çukurova Üniversitesi, Mühendislik Fakültesi, Maden Mühendisliği Bölümü, Adana

Geliș tarihi: 27.11.2020 Kabul tarihi: 30.12 .2020

$\ddot{\mathbf{O z}}$

Doğal taşlar binalarda genellikle yapı ve kaplama taşı olarak kullanılmaktadırlar. Yangın gibi dış etkenler binalara hem yapısal hem de estetik açıdan geri dönüşü olmayan zararlar vermektedir. Yüksek sıcaklıklar doğal taşın yüzey ve içyapı özelliklerinde hasara neden olabilmektedirler. Doğal taşların bu hasardan etkilenme derecelerinin önceden bilinmesi kullanım yerinin seçilmesi açısından önemlidir. Bu çalışmada, yüksek sıcaklığın doğal taşların iç yapı, parlaklık ve pürüzlülük özelliklerine etkileri araştırılmıştır. Bu amaçla, doğal taş numuneleri $100^{\circ} \mathrm{C}$ ile $900^{\circ} \mathrm{C}$ arasındaki sıcaklıklara 1sıtılarak bu sicaklıklarda 1 saat bekletilmiştir. Daha sonra doğal taş numunelerinin petrografik, yüzey parlaklık ve yüzey pürüzlülük özellikleri belirlenmiştir. Sonuç olarak, yüksek sıcaklığın $\left(700^{\circ} \mathrm{C}\right.$ ve üzeri) doğal taşların mineralojik yapısında bozulmalara neden olmasından dolayı numunelerin parlaklık değerlerinde azalış ve pürüzlülük değerlerinde artış gözlenmiştir.

Anahtar Kelimeler: Doğal taşlar, Yüksek sıcaklık, Petrografik özellik, Parlaklık, Pürüzlülük

\section{The Influence of High Temperature on the Petrographical, Gloss and Roughness Properties of Natural Stones}

\begin{abstract}
Natural stones are generally used in buildings as building and covering stones. External factors such as fire cause irreversible damage to buildings both structurally and aesthetically. High temperatures can

\footnotetext{
*Sorumlu yazar (Corresponding author): Zehra Funda TÜRKMENOĞLU, fundaturkmenoglu@yyu.edu.tr
} 
cause damage to the surface and microstructure of natural stone. It is important to know the degree of damage of natural stones in advance in terms of choosing the place of use. In this study, the effects of high temperature on the petrographical, gloss and roughness of natural stones were investigated. To this end, natural stone samples were heated between $100^{\circ} \mathrm{C}$ and $900^{\circ} \mathrm{C}$ temperatures and kept for 1 hour at these temperatures. Then, the petrographical, gloss and roughness properties of natural stone samples were determined. As a result, a decrease in the gloss values and an increase in the roughness values of the samples were observed due to the deterioration of the mineralogical structure of natural stones at $700^{\circ} \mathrm{C}$ and above temperatures.

Keywords: Natural stones, High temperature, Petrographical properties, Gloss, Roughness

\section{GíRiş}

Doğal taşlar binalar, köprüler ve tüneller gibi birçok yapıda yaygın olarak kullanılmaktadır. Doğal taşlar yangın gibi yüksek sıcaklık etkilerine maruz kaldıklarında hasar görürler. Yüksek sıcaklığa maruziyet doğal taşın fiziksel, kimyasal, mekanik ve içyapı özelliklerinde bozulmaya neden olur [1,2]. Yüksek sicaklıklara maruz kalan mermerlerde bir dizi mikro çatlak oluşumu, parçalanma ve renk değişimi gibi değişiklikler meydana gelir. Bunlardan başka kayacın mineralojik yap1 ve yüzey doku özellikleri de yüksek sıcaklıktan etkilenir. Doğal taşlar 1sı gibi dış etkilere maruz kaldıklarında kristal tanelerinin sınır boylarında gerçekleşen genleşme taşın petrografik dokusunun bozulmasina neden olur [3]. Mermer 1sitıldığında, mineral taneleri arasındaki farklı termal özellikler nedeniyle, düzensiz termal gerilmeler gelişir [4]. Mineral tanelerinin termal gerilmeleri belirli bir sınırı aştığında ise taneler arasında çatlak meydana gelir. Sıcaklığın artması hem çatlak sayılarını artırır hem de taneler arası çatlakları genişletir, bu da kayacın mekanik özelliklerinin sürekli olarak zayıflamasına neden olur. Sıcaklık $600^{\circ} \mathrm{C}$ 'nin üzerine çıktığında, çok sayıda kristaller arası çatlakların başlamasıyla birlikte taneler arası çatlaklar yayılır. Kalsit ve dolomit gibi ana mineraller $800^{\circ} \mathrm{C}$ 'de daha dramatik bir şekilde ayrışır. Mermer, mekanik özelliklerin daha da kötüleşmesine yol açan geri dönüşü olmayan termal hasarlar oluşur [5-9]. Petrografik doku dişında taşın yüzey özellikleri de sıcaklık etkisi ile değişikliğe uğrar. Genellikle bir doğal taşın pazarlanmasında yüzey parlaklık ve pürüzlülük değerinin yüksek olması tercih edilir.
Bu amaçla da doğal taşlar piyasaya sunulmadan önce cilalama işlemine tabi tutularak yüzey kalite özellikleri iyileştirilir. Yüzey parlaklık ölçümü genellikle mermer plakalarının cilalama işlemi sonrasında yüzey kalitesini belirlemek amacıyla yapılan bir kalite kontrol parametresidir. Parlaklık tanım olarak bir yüzeye gelen 1şın yoğunluğunun, yüzeyden yansıyan ışın yoğunluğuna oranıdır. Malzemenin yüzey özelliği ile ışığın yansıma kabiliyeti arasında doğrusal bir ilişki bulunmaktadır. Yüzeyi pürüzlü olan malzemelerde 1şık düzgün bir şekilde yansımadığından yüzey parlaklık değeri de azdır. Bunun aksine pürüzsüz yüzeylerde gelen 1şın, yönünü geldiği açı ile tamamen değiştirir ve yüksek parlaklık değeri elde edilir [7]. Doğal taşların parlaklık özelliği gibi pürüzlülük özelliği de önemli bir kalite kontrol parametresidir. Yüzey pürüzlülüğü, genellikle pürüzlülük olarak kısaltılan, yüzey dokusunun bir bileşenidir. Gerçek bir yüzeyin ideal biçiminden normal vektörü yönündeki sapmalar ile ölçülür. Bu sapmalar büyükse, yüzey pürüzlüdür eğer sapmalar küçükse yüzey pürüzsüzdür. Literatür çalışmaları incelendiğinde, yüksek sicaklıkların doğal taş özelliklerine olan etkilerinin belirlendiği birçok çalışma olduğu görülmüştür. $\mathrm{Bu}$ çalışmaların büyük çoğunluğunda yüksek sıcaklığın taşın mekanik özelliklerine olan etkileri araştırılmıştır [8-11]. Ancak, yüksek sıcaklığın doğal taşların mikroyap1, yüzey parlaklık ve pürüzlülük gibi özelliklerine olan etkilerinin araştırıldığı çalışmaların sayısı oldukça sınırlıdır [12-20]. Chakrabarti ve arkadaşları [1] yaptıkları çalışmada yangının doğal taşın fiziksel ve mekanik özelliklerine olan etkisini araştırmıştır. Sıcaklık artışının mermerlerin fiziksel ve mekanik 
özelliklerini olumsuz yönde etkilediği ve mermerlerde ufalanma, parçalanma ve dayanım kaybına neden olduğunu bildirmişlerdir. Özgüven ve Özçelik [9], çalışmalarında kireçtaşı ve mermerleri oda sıcaklığından $1000^{\circ} \mathrm{C}$ 'ye kadar değişen yüksek sıcaklıklara maruz bırakmışlardır. Çalışma sonunda $600^{\circ} \mathrm{C}$ 'ye kadar doğal taşlarda renk değişimi ve hasarın çok az oranda olduğunu belirtmişlerdir. Şengün, [11] karbonatlı kayaçların yüksek sıcaklık etkisini araştırdığı çalışmasında. $300^{\circ} \mathrm{C}$ gibi düşük sıcaklıkların kayaçların fiziksel ve mekanik özellikleri üzerindeki etkisinin çok sınırlı olduğunu bildirmiştir. Ayrıca. $600^{\circ} \mathrm{C}$ 'nin üzerindeki sıcaklıklarda kayaçların gözeneklilik değerlerinde artış olurken dayanım ve ultrases geçiş hızı gibi özelliklerinde ise azalış olduğunu belirlemiştir. Gomez ve arkadaşları [15] çalışmalarında yüksek sıcaklığın kireçtaşlarının kimyasal bileşim. mikroyapı ve gözeneklilik özelliğine olan etkilerini araştırmışlardır. Sıcaklık değişimlerinin kireçtaşlarının içsel özelliklerini etkileyerek kayaç içinde yeni kırılmalara ve mikro çatlaklara neden olduğunu ve ayrıca sıcaklığın kireçtaşlarında renk değişikliğe sebep olduğunu belirlemişlerdir. Kireçtaşlarının içerisinde bulunan az miktarda demirli mineralin bile oksitlenmeden dolayı önemli renk değişikliklerine neden olduğunu belirtmişlerdir. Erdoğan [16] yaptığ1 çalışmasında kayaçların yüzey parlaklık değerinin olumsuz yönde etkilenmesine porozite, farklı kristal sınırları, mikro çatlaklardaki dolgular, kristal yönlenme ve kesme düzlemi arasındaki eğiklik gibi parametrelerin etki ettiğini bildirmiş̧ir. Bu çalışmada, inşaat ve yapı malzemeleri alanında yaygın olarak kullanılan kireçtaşı kökenli doğal taşların yüksek sıcaklık etkisi sonrası petrografik yapı, parlaklık ve pürüzlülük özelliklerindeki değişiklikler incelenmiştir.

\section{MATERYAL ve METOD}

\subsection{Kullanılan Malzemeler}

\subsubsection{Doğal Taşlar}

Çalışmada, Van yöresinde bulunan bir mermer işletmesinden temin edilen altı farklı doğal taş numunesi kullanılmıştır. Deneysel çalışmalarda, $5 \times 5 \times 2 \mathrm{~cm}$ ebatlarında prizma şeklinde numuneler kullanılmıştır. Numunelerin ticari isimleri sırasıyla Kalecik (KL), Yaramış (YR), Pervari (PR), Tamara Bej (TB), Tamara Brown (TN) ve Roza Vera (RV)'dır. Yüksek sıcaklık deneylerinde kullanılan doğal taş numunelerine ait görünümler Şekil 1'de verilmiştir.

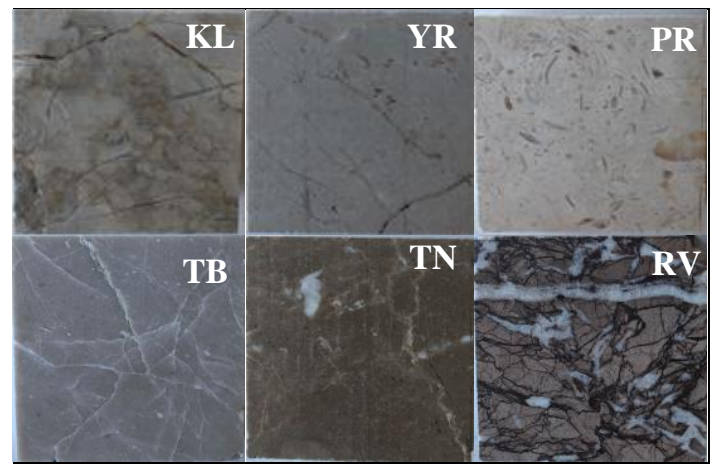

Şekil 1. Doğal taş numunelerine ait görünüm

\subsection{Metod}

\subsubsection{Yüksek Sicaklık Deneyi}

Doğal taşlar, yangın gibi etkilere maruz kalabilirler. Sıcaklık değişiminin doğal taş özelliklerine olan etkilerini belirlemek için, genellikle laboratuvar ortamında yangın simülasyon deneyleri gerçekleştirilmektedir. Yangın sirasında sicaklığın $1200^{\circ} \mathrm{C}^{\prime}$ ye kadar çıktığı bilinmektedir [22,23]. $\mathrm{Bu}$ çalışmada, yangın sirasında sicaklığın maksimum $900^{\circ} \mathrm{C}$ 'ye kadar çıktığı ve bir saat sürdüğü varsayılmıştır. Doğal taş numuneleri laboratuvarda firın içerisinde $100^{\circ} \mathrm{C}$ ile $900^{\circ} \mathrm{C}$ arasindaki sicakliklarda bir saat süreyle bekletilmiştir. Daha sonra numuneler firından çıkarılarak desikatör içerisinde soğutulmuştur. Soğuyan numunelerin parlaklık ve pürüzlülük değerleri incelenmiştir. Deneylerde, Van Yüzüncü Yil Üniversitesi Maden Mühendisliği Bölüm Laboratuvarında bulunan Protherm Marka bir kül firını kullanılmıştır. Yüksek sıcaklık deneyi sonrası doğal taş numunelerine ait görünümler Şekil 2'de verilmişsir. 


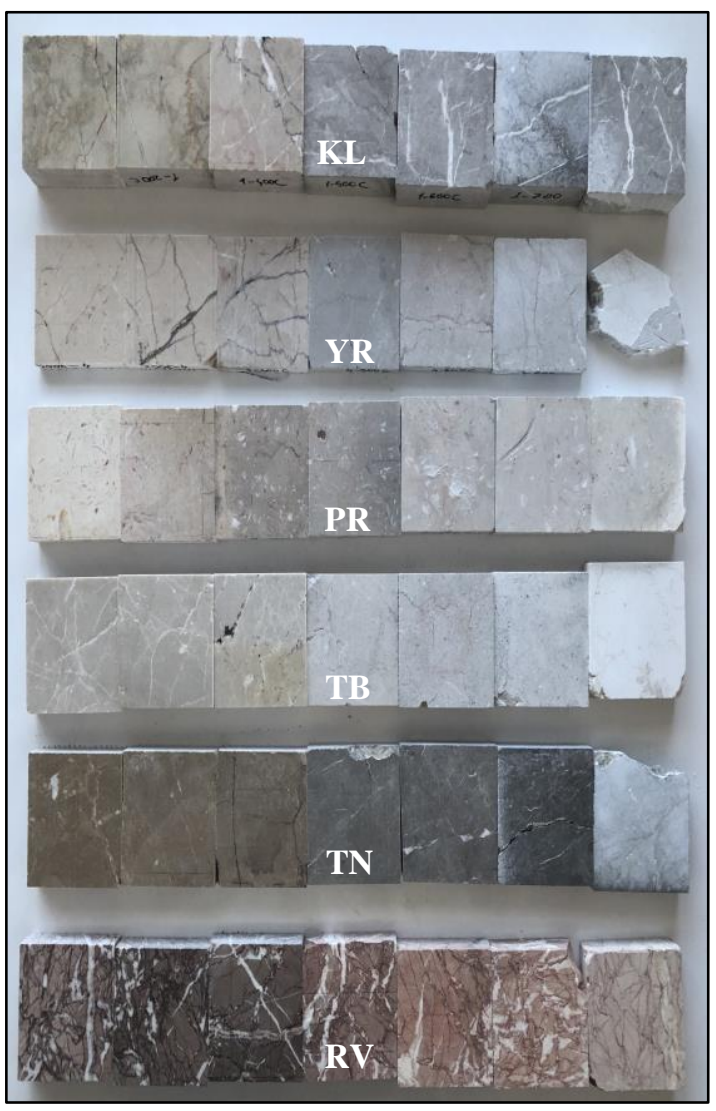

Şekil 2. Yüksek sıcaklık deneyi sonrası numuneler

\subsubsection{Petrografik Özelliklerin Belirlenmesi}

Çalışma kapsamında farklı sıcaklık uygulanmış doğal taş numunelerinin polarizan mikroskop yöntemi yardımıla petrografik özellikleri incelenmiştir. Petrografik analizlerde TS EN 12407 [25] standardından yararlanılmıştır.

\subsubsection{Yüzey Parlaklık Ölçümü}

Çalışmada kullanılan doğal taş numunelerinin yüzeylerinde yüzey parlaklık ölçümü gerçekleştirilmiş̧ir. Parlaklık ölçümleri PCEGM100 marka bir parlaklık ölçüm cihazı ile yapılmıştır. Parlaklık ölçümleri için $5 \times 5 \times 2 \mathrm{~cm}$ ebatlarında numuneler kullanılmış ve her plaka yüzeyinden 3 adet okuma yapılmıştır. Bu çalışmada $60^{\circ}$ lik ölçüm açısı kullanılmıştır. Doğal taş numunelerine ait yüzey parlaklık ölçüm görüntüsü Şekil 3 'te verilmiştir.

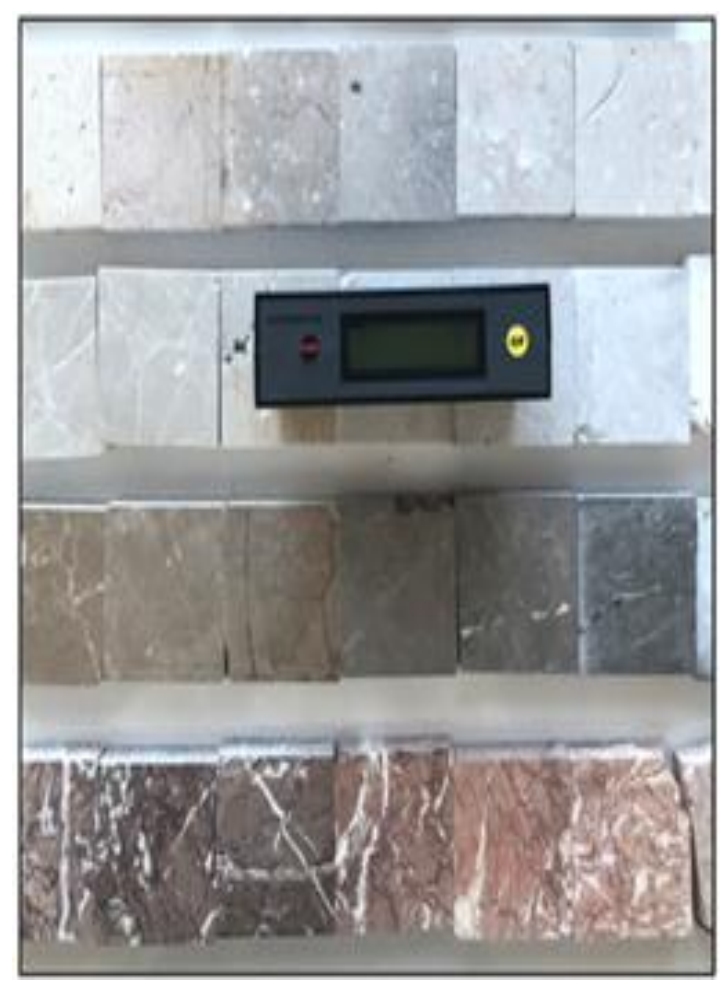

Şekil 3. Yüzey parlaklık değer ölçümü

\subsubsection{Yüzey Pürüzlülük Ölçümü}

Doğal taşın yüzeyindeki mikro ölçekteki yükselti değişiminin belirlenmesi amaciyla yüzey pürüzlülük ölçümü yapılmıştır. Doğal taş numunelerinin pürüzlülük ölçümlerinin belirlenmesinde $\mathrm{Ra}, \mathrm{Rq}$ ve $\mathrm{Rz}$ parametrelerini ölçebilen PCE-RT11 marka bir pürüzlülük ölçüm cihazı kullanılmıştır. Ra parametresi doğal taş kalite kontrolünde (aritmetik ortalama yüksekliği) en sık kullanılan uluslararası pürüzlülük parametresidir. Rq (karekök ortalama pürüzlülüğü) parametresi yüzey yükseklikleri dağılımının standart sapmasını göstermektedir. Rz parametresi ise, ölçülen yüzeydeki en yüksek beş nokta değeri toplamının en düşük beş nokta değeri toplamının ortalamasıyla elde edilen sayıdır. Yüzey pürüzlülük değer ölçümü yapılan numunelere ait görünüm Şekil 4'te verilmiş̧ir. 


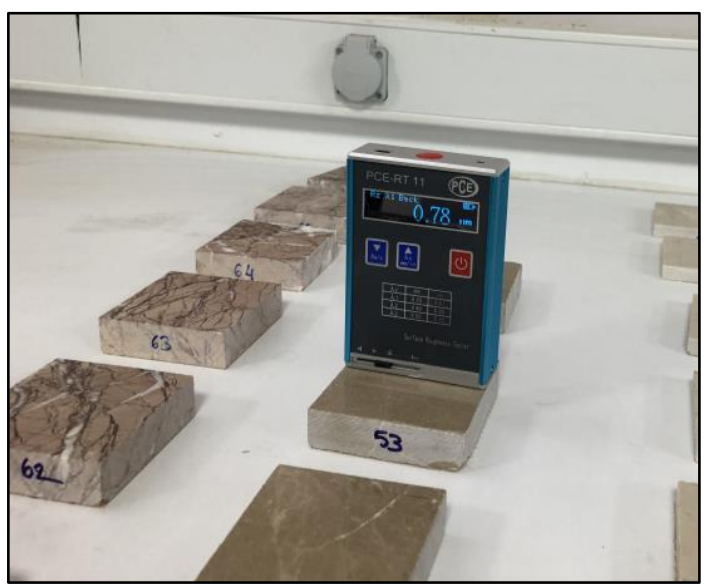

Şekil 4. Yüzey pürüzlülük değer ölçümü

\section{BULGULAR ve TARTIŞMA}

\subsection{Petrografik Analiz Sonuçları}

Petrografik analizler, $200^{\circ} \mathrm{C}, 600^{\circ} \mathrm{C}, 700^{\circ} \mathrm{C}, 800^{\circ} \mathrm{C}$ ve $900^{\circ} \mathrm{C}$ sıcaklığa maruz kalmış doğal taş numuneleri üzerinde gerçekleştirilmiştir. Yüksek sıcaklıklara maruz kalmış doğal taş numunelerine ait petrografik tanımlama ve ince kesit görüntüleri Çizelge 1 ile Çizelge 6 arasında verilmiştir. Petrografik analizler neticesinde tüm kireçtaş1 numunelerinin ana bileşeninin kalsit olduğu tespit edilmiştir. Petrografik analizler neticesinde tüm kireçtaşı numunelerinin ana bileşeninin kalsit olduğu tespit edilmiştir. Petrografik incelemeler neticesinde, genel olarak $700^{\circ} \mathrm{C}$ sicaklıktan itibaren tüm numunelerde kalsit kristallerinde irileşme ve granoblastik doku oluşumu görülmüştür. $\mathrm{Bu}$ da kireçtaş1 numunelerinde rekristalizasyonun başladığını göstermektedir. Ayrıca, tüm numunelerin hamur renginde koyulaşma ve fosil izlerinde değişim gözlenmiştir. $800^{\circ} \mathrm{C}$ sicaklıkta ise tüm numunelerin içindeki fosil kavkıların büyük oranda yok olduğu ve kalsit mineralinde bozulma olduğu tespit edilmiştir. $900^{\circ} \mathrm{C}$ sicaklık sonrasinda ise tüm numunelerde kalsit kristallerinin kaybolduğu ve karbonatlı yapının tamamen altere olduğu gözlenmiştir.

Çizelge 1. Kalecik numunesine ait petrografik analiz

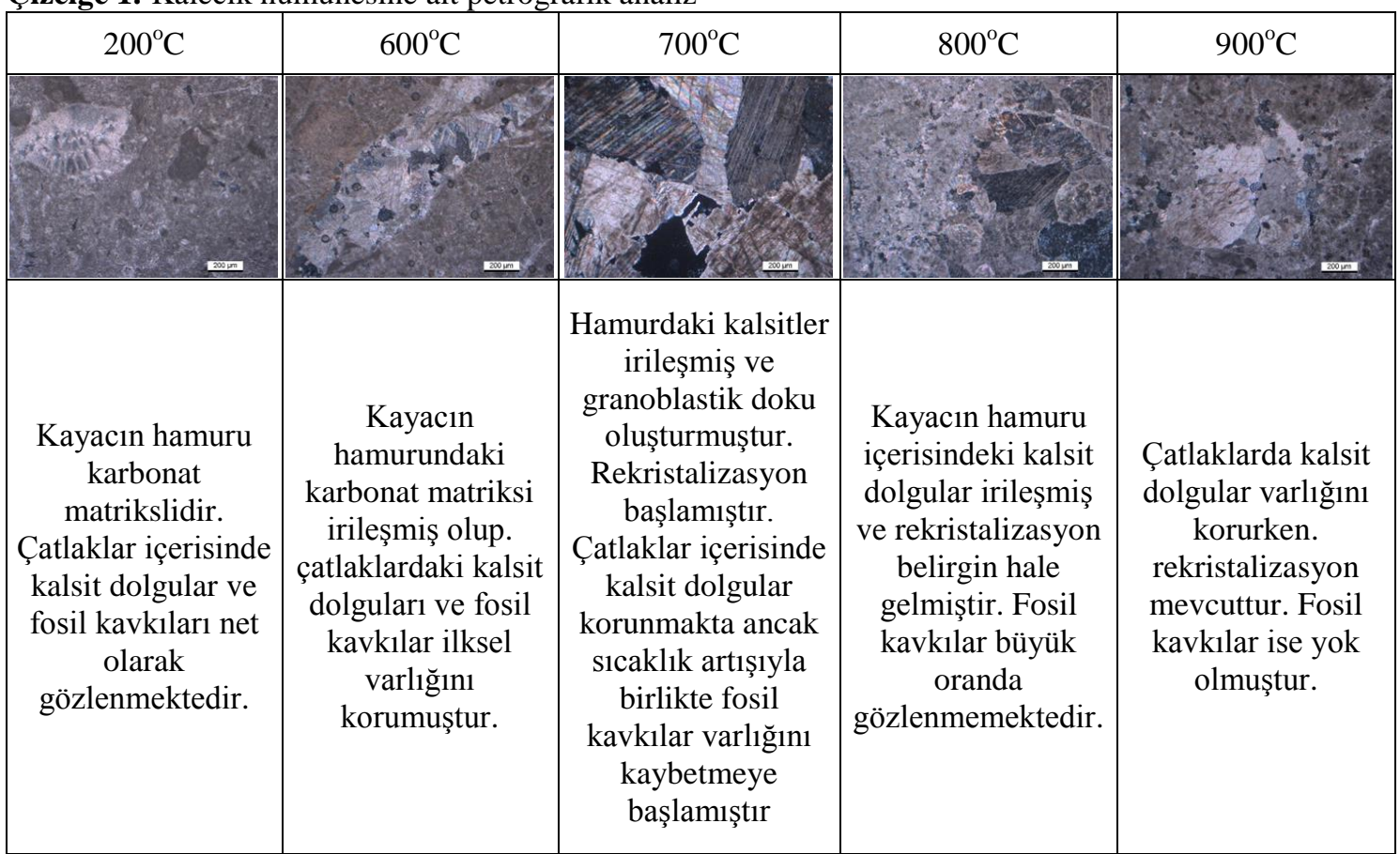


Çizelge 2. Yaramıș numunesine ait petrografik analiz

\begin{tabular}{|c|c|c|c|c|}
\hline $200^{\circ} \mathrm{C}$ & $600^{\circ} \mathrm{C}$ & $700^{\circ} \mathrm{C}$ & $800^{\circ} \mathrm{C}$ & $900^{\circ} \mathrm{C}$ \\
\hline 9. $\mathrm{sm}$ & $1.47+5 \mathrm{mon}$ & 10. & 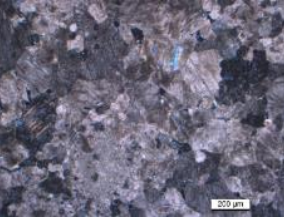 & 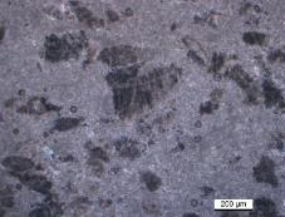 \\
\hline $\begin{array}{l}\text { Kayacın doğal } \\
\text { yapısında kısmen } \\
\text { rekristalizasyon } \\
\text { mevcut iken } \\
\text { çatlaklarda iri kalsit } \\
\text { dolguları } \\
\text { gözlenmektedir. } \\
\text { Fosil kavkıları ise } \\
\text { gözlenmemektedir. }\end{array}$ & $\begin{array}{c}\text { Kayacın doğal } \\
\text { yapısında çok ciddi } \\
\text { değişim } \\
\text { gözlenmemektedir. } \\
\text { Kayaç içerisinde } \\
\text { fosil kavkılar } \\
\text { gözlenmemektedir. }\end{array}$ & $\begin{array}{l}\text { Genel olarak bir } \\
\text { değişim } \\
\text { görülmemiştir aynı } \\
\text { zamanda kalsit ve } \\
\text { kalsit dolguları } \\
\text { mevcuttur. }\end{array}$ & $\begin{array}{l}\text { Hamurda gözlenen } \\
\text { kalsitler sıcaklık } \\
\text { artışılyla birlikte } \\
\text { irileşmiş iken } \\
\text { granoblastik } \\
\text { dokuya doğru geçiş } \\
\text { görülmektedir. }\end{array}$ & $\begin{array}{l}\text { Kalsit kristallerinde } \\
\text { renk değişimleri } \\
\text { başlamış ve aynı } \\
\text { zamanda dilinim } \\
\text { izleri ovalleşmiştir. } \\
\text { Kalsitin dıştan içe } \\
\text { doğru girişim } \\
\text { rengi, 4. diziden } \\
\text { (parlak. Canl, } \\
\text { pastel tonlar), } \\
\text { 2. diziye (donuk ve } \\
\text { mat tonlar) geçiş } \\
\text { göstermiştir. }\end{array}$ \\
\hline
\end{tabular}

Çizelge 3. Pervari numunesine ait petrografik analiz

\begin{tabular}{|c|c|c|c|c|}
\hline $200^{\circ} \mathrm{C}$ & $600^{\circ} \mathrm{C}$ & $700^{\circ} \mathrm{C}$ & $800^{\circ} \mathrm{C}$ & $900^{\circ} \mathrm{C}$ \\
\hline$\Rightarrow \mathrm{som}$ & & & & 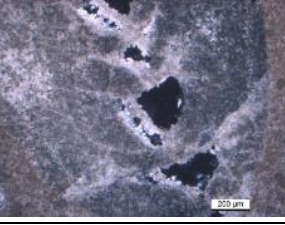 \\
\hline $\begin{array}{c}\text { Hamuru } \\
\text { karbonattan } \\
\text { oluşmaktadır. İri ve } \\
\text { bol fosilli bir örnek } \\
\text { olup kalsit } \\
\text { kristalleri } \\
\text { nummulite fosilini } \\
\text { içermektedir. }\end{array}$ & $\begin{array}{c}\text { Nummulite } \\
\text { fosilleri kısmen } \\
\text { korunmakta ancak } \\
\text { kavkılarında renk } \\
\text { değişimleri } \\
\text { başlamıştır. }\end{array}$ & $\begin{array}{l}\text { Hamurun genel } \\
\text { görünümünde } \\
\text { koyulaşma } \\
\text { hakimdir. Halen } \\
\text { fosil kavkıları } \\
\text { görülürken fosiller } \\
\text { parçalanmış, renk } \\
\text { değişimine } \\
\text { uğramış, miktarca } \\
\text { azalmış ve iriliğini } \\
\text { kaybetmiştir. }\end{array}$ & $\begin{array}{c}\text { Fosil kavkılar } \\
\text { ovalleşmeye doğru } \\
\text { eğilim gösterirken, } \\
700^{\circ} \mathrm{C} \text { 'de gözlenen } \\
\text { özellikler varlığını } \\
\text { korumaktadır. }\end{array}$ & $\begin{array}{l}\text { Örneğin genel } \\
\text { fiziki özelliklerinde } \\
\text { değişim geliştiği } \\
\text { gözlenmekte ve } \\
\text { ayrıca, fosil } \\
\text { kavkılarında ise } \\
\text { daha fazla } \\
\text { merkezden kırılma } \\
\text { gözlenmektedir. }\end{array}$ \\
\hline
\end{tabular}


Çizelge 4. Tamara Bej numunesine ait petrografik analiz

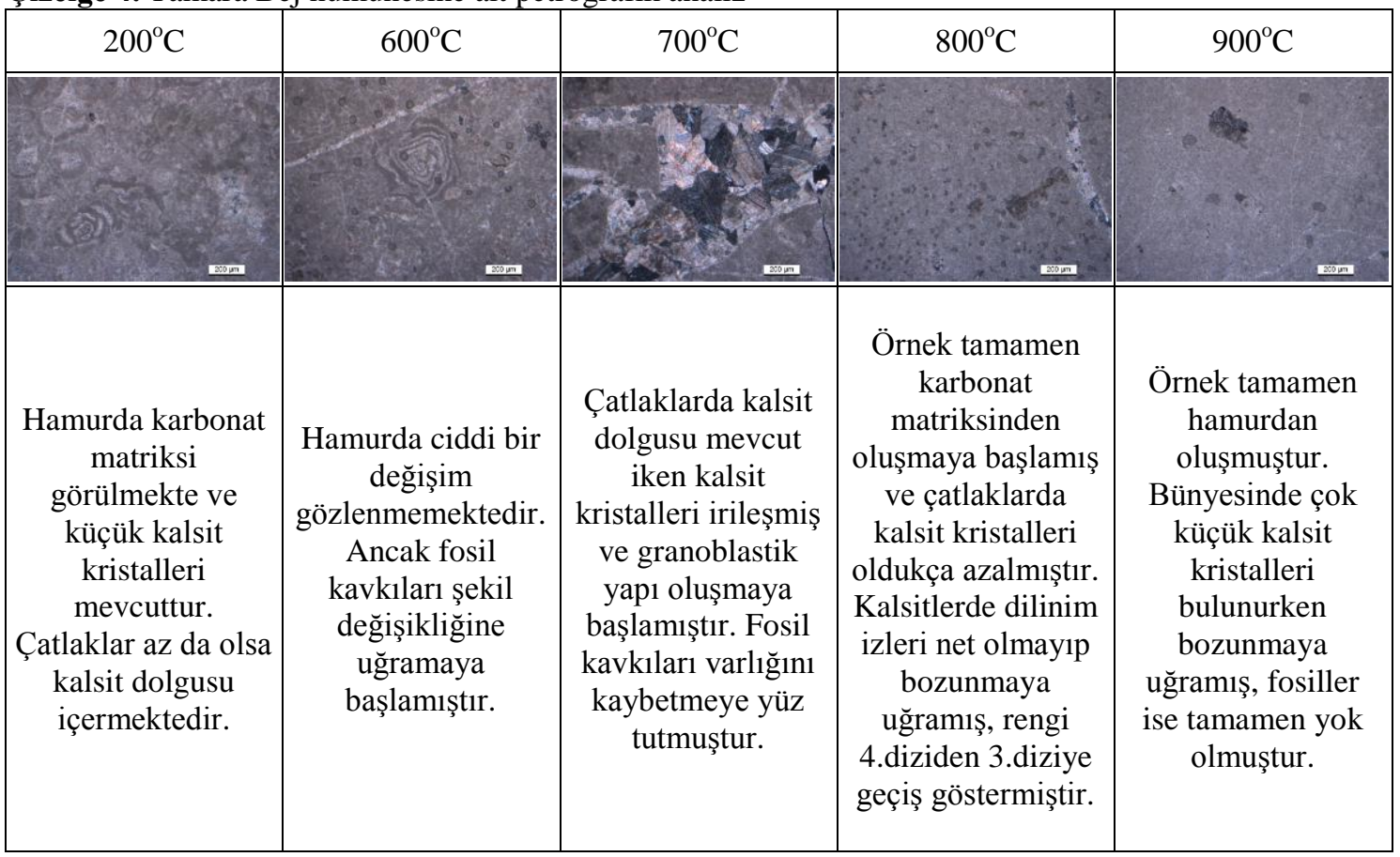

Çizelge 5. Tamara Brown numunesine ait petrografik analiz

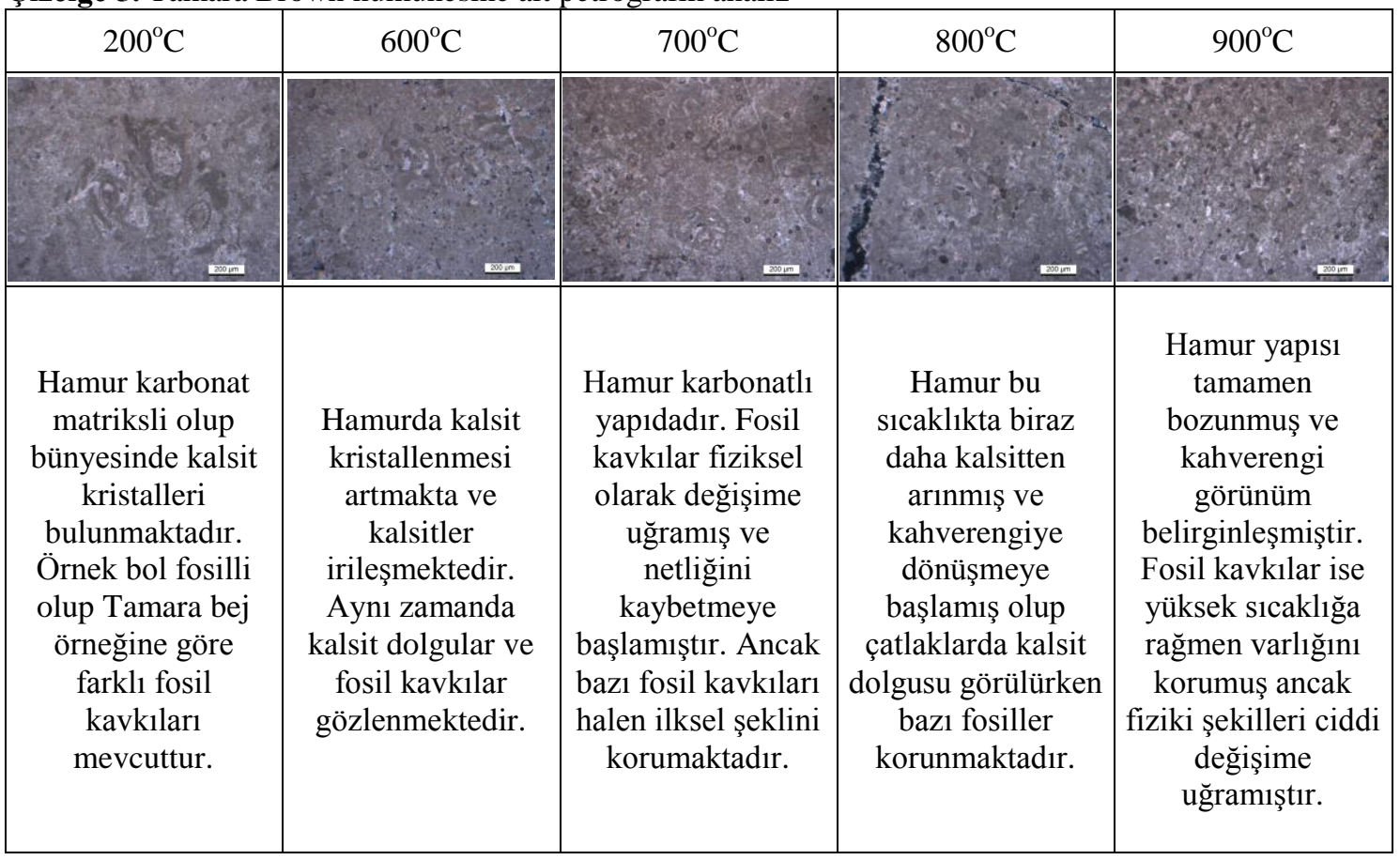


Çizelge 6. Roza Vera numunesine ait petrografik analiz

\begin{tabular}{|c|c|c|c|c|}
\hline $200^{\circ} \mathrm{C}$ & $600^{\circ} \mathrm{C}$ & $700^{\circ} \mathrm{C}$ & $800^{\circ} \mathrm{C}$ & $900^{\circ} \mathrm{C}$ \\
\hline$x^{4} x^{4} x^{3}$ & 87 in $\quad 1$ rom & 32 & & at \\
\hline $\begin{array}{c}\text { Petrografik adı } \\
\text { kireçtaşı } \\
\text { mermeridir. Bol } \\
\text { çatlaklı olup } \\
\text { çatlaklarda kalsit } \\
\text { ve demir oksitler } \\
\text { bulunmaktadır. } \\
\text { Hamur, ince taneli } \\
\text { ve karbonat-kil? } \\
\text { katkılıdır. } \\
\text { Hamurun içinde } \\
\text { irili ufaklı kalsit } \\
\text { kristalleri } \\
\text { mevcuttur. }\end{array}$ & $\begin{array}{c}\text { Çatlaklardaki } \\
\text { kalsitler irileşerek } \\
\text { granoblastik yapıya } \\
\text { dönüşmektedir ve } \\
200^{\circ} \mathrm{C}^{\prime} \text { deki örnek } \\
\text { ile hemen hemen } \\
\text { aynı özellikler } \\
\text { gözlenmektedir. }\end{array}$ & $\begin{array}{c}\text { Hamurda biraz } \\
\text { daha kalsit } \\
\text { kristalleri } \\
\text { belirginleşmiştir. } \\
\text { Çatlaklardaki kalsit } \\
\text { kristalleri } 600^{\circ} \mathrm{C} \\
\text { sicaklıktaki örnek } \\
\text { ile aynı } \\
\text { düzeydedir. }\end{array}$ & $\begin{array}{l}\text { Hamurda } \\
\text { killeşmeler (kil } \\
\text { minerallerinin } \\
\text { bozulması) } \\
\text { gözlenmekte ve } \\
\text { kalsit kristalleri } \\
\text { irileşmektedir. } \\
\text { Demir oksit hala } \\
\text { mevcuttur. }\end{array}$ & $\begin{array}{c}\text { Hamurda kalsit } \\
\text { kristalleri hala } \\
\text { mevcuttur fakat } \\
\text { karbonatlı yapı } \\
\text { tamamen altere } \\
\text { olmuş ve } \\
\text { killeşmiştir. } \\
\text { Damarlarda yer } \\
\text { alan kalsit ve demir } \\
\text { oksit hakimiyetini } \\
\text { korumaktadır. }\end{array}$ \\
\hline
\end{tabular}

\subsection{Yüzey Parlaklık Ölçüm Sonuçları}

Doğal taş numunelerine ait yüzey parlaklık ölçüm sonuçları Çizelge 7'de verilmiştir. Bu çalışmada, parlaklık okuma değerleri için $60^{\circ}$ 'lik ölçüm açısı kullanılmıştır. Yüzey parlaklık ölçüm sonuçları incelendiğinde, tüm numunelerin sıcaklık artışına bağlı olarak yüzey parlaklık değerlerinin azaldığı tespit edilmiştir. Parlaklık değerlerinde en fazla düşüşün olduğu sıcaklık 700 C'dir. Bu sıcaklıktan itibaren kalsit mineralinin yapısının hızla bozulduğu ve taşın yüzey parlaklık değerinde azalışa neden olduğu düşünülmektedir. Ayrıca, RV numunesi en düşük parlaklık değerine sahip olan numunedir. $\mathrm{Bu}$ numune diğerlerine kıyasla farklı mineralojik bileşenlere sahiptir ve içeriğinde kalsit minerali dışında mineral (demir) içermektedir. Gürcan ve arkadaşları [19] ana mineral kalsitin dışında biyotit gibi demirce zengin minerallerin varlığının taşların yüzey parlaklık özelliğini azalttığını belirtmişlerdir.
Cizelge 7. Yüzey parlaklık ölçüm sonuçları

\begin{tabular}{|c|c|c|c|c|c|c|}
\hline \multirow{2}{*}{${ }^{\circ} \mathrm{C}$} & \multicolumn{6}{|c|}{ Parlaklık $\left(60^{\circ}\right)$} \\
\cline { 2 - 7 } & $\mathrm{KL}$ & YR & PR & TB & TN & RV \\
\hline 100 & 38,2 & 46,5 & 36,2 & 38,2 & 30,5 & 4,5 \\
\hline 200 & 34,6 & 40,4 & 35,8 & 33,7 & 31,4 & 4,6 \\
\hline 300 & 30,3 & 42,9 & 33,4 & 31,7 & 29,5 & 4,4 \\
\hline 400 & 29,2 & 41,6 & 32,5 & 30,3 & 28,3 & 4.2 \\
\hline 500 & 26,9 & 40,1 & 30,2 & 26,6 & 25,1 & 4.5 \\
\hline 600 & 25,1 & 38,5 & 24,6 & 22,7 & 21,5 & 4.0 \\
\hline 700 & 18,9 & 21,7 & 15,5 & 19,9 & 14,8 & 3.5 \\
\hline 800 & 9,3 & 10,8 & 8,5 & 8,7 & 6,4 & 2.8 \\
\hline 900 & - & - & - & - & - & - \\
\hline
\end{tabular}




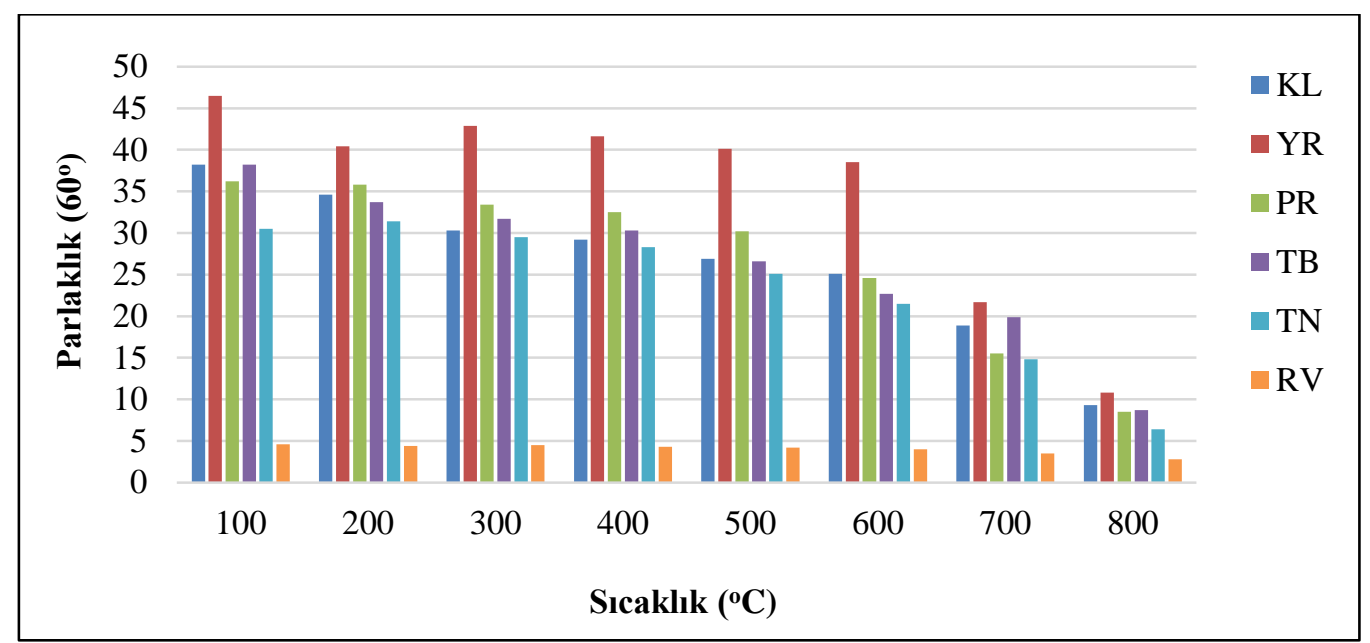

Şekil 7. Yüksek sıcaklık ve parlaklık değişimleri

\subsection{Yüzey Pürüzlülük Ölçüm Sonuçları}

Doğal taş numunelerine ait yüzey pürüzlülük ölçüm sonuçları Çizelge 8'de verilmiştir.

Ölçüm sonuçları incelendiğinde $100^{\circ} \mathrm{C}$ ile $600^{\circ} \mathrm{C}$ sıcaklıklar için pürüzlülük değerleri arasında doğrusal bir ilişki gözlenmemiştir. Numunelerin
Ra pürüzlülük değerleri $600^{\circ} \mathrm{C}^{\prime}$ ye kadar $0,05 \mu \mathrm{m}$ ile $0,15 \mu \mathrm{m}$ arasındadır. $700^{\circ} \mathrm{C}$ ve üzerindeki sıcaklıklarda tüm numunelerin pürüzlülük değerlerinde artış olduğu tespit edilmiştir.

Bunun nedeni çatlak oluşumunun artması ve kristal kararlılığın azalması olabilir. Ayrıca, $900^{\circ} \mathrm{C}$ sıcaklıkta doğal taşlarda bozunma fazla

Çizelge 8. Yüzey pürüzlülük ölçüm sonuçları

\begin{tabular}{|c|c|c|c|c|c|c|c|c|c|c|}
\hline & & \multicolumn{10}{|c|}{ Sicaklı $\left({ }^{\circ} \mathrm{C}\right)$} \\
\cline { 3 - 12 } & & 100 & 200 & 300 & 400 & 500 & 600 & 700 & 800 & 900 \\
\hline \multirow{3}{*}{ KL } & $\mathrm{Ra}$ & 0,08 & 0,10 & 0,12 & 0,13 & 0,11 & 0,13 & 0,18 & 0,20 & - \\
\cline { 2 - 12 } & $\mathrm{Rq}$ & 0,10 & 0,12 & 0,13 & 0,16 & 0,11 & 0,14 & 0,17 & 0,24 & - \\
\cline { 2 - 12 } & $\mathrm{Rz}$ & 0,55 & 0,61 & 0,65 & 0,65 & 0,64 & 0,58 & 0,70 & 0,85 & - \\
\hline \multirow{3}{*}{ YR } & $\mathrm{Ra}$ & 0,05 & 0,09 & 0,12 & 0,11 & 0,14 & 0,13 & 0,15 & 0,16 & \\
\cline { 2 - 12 } & $\mathrm{Rq}$ & 0,12 & 0,15 & 0,15 & 0,24 & 0,17 & 0,11 & 0,35 & 0,09 & - \\
\cline { 2 - 11 } & $\mathrm{Rz}$ & 0,45 & 0,56 & 0,60 & 0,62 & 0,57 & 0,47 & 0,68 & 0,39 & - \\
\hline \multirow{3}{*}{$\mathrm{PR}$} & $\mathrm{Ra}$ & 0,07 & 0,09 & 0,14 & 0,11 & 0,13 & 0,12 & 0,16 & 0,19 & - \\
\cline { 2 - 12 } & $\mathrm{Rq}$ & 0,10 & 0,13 & 0,18 & 0,14 & 0,19 & 0,21 & 0,19 & 0,23 & - \\
\cline { 2 - 11 } & $\mathrm{Rz}$ & 0,52 & 0,64 & 0,70 & 0,68 & 0,78 & 0,75 & 0,82 & 0,88 & - \\
\hline \multirow{3}{*}{$\mathrm{TB}$} & $\mathrm{Ra}$ & 0,10 & 0,11 & 0,12 & 0,14 & 0,10 & 0,14 & 0,15 & 0,17 & - \\
\cline { 2 - 11 } & $\mathrm{Rq}$ & 0,14 & 0,18 & 0,20 & 0,20 & 0,17 & 0,15 & 0,23 & 0,32 & - \\
\cline { 2 - 11 } & $\mathrm{Rz}$ & 0,58 & 0,79 & 0,75 & 0,77 & 0,72 & 0,62 & 0,84 & 0,86 & - \\
\hline \multirow{3}{*}{$\mathrm{TN}$} & $\mathrm{Ra}$ & 0,08 & 0,10 & 0,09 & 0,12 & 0,13 & 0,14 & 0,17 & 0,19 & - \\
\cline { 2 - 11 } & $\mathrm{Rq}$ & 0,08 & 0,16 & 0,32 & 0,20 & 0,18 & 0,24 & 0,25 & 0,30 & - \\
\cline { 2 - 11 } & $\mathrm{Rz}$ & 0,50 & 0,75 & 0,60 & 0,68 & 0,74 & 0,76 & 0,79 & 0,80 & - \\
\hline \multirow{3}{*}{$\mathrm{RV}$} & $\mathrm{Ra}$ & 0,12 & 0,13 & 0,12 & 0,14 & 0,15 & 0,15 & 0,21 & 0,25 & - \\
\cline { 2 - 10 } & $\mathrm{Rq}$ & 0,16 & 0,20 & 0,24 & 0,21 & 0,18 & 0,11 & 0,18 & 0,20 & - \\
\cline { 2 - 10 } & $\mathrm{Rz}$ & 0,65 & 0,75 & 0,88 & 0,87 & 0,80 & 0,86 & 0,87 & 0,91 & - \\
\hline
\end{tabular}


olduğundan dolayı pürüzlülük değeri ölçülememiştir. RV numunesinin pürüzlülük değerleri diğer numunelere kıyasla fazladır. RV numunesi içerisinde kalsit minerali dışında ikincil koyu renkli (demir minerali) mineral bulunmaktadır. Demir mineralinin varlığı ve kayaç içerisindeki dağılım ve oranının pürüzlülük değerininim artmasina neden olduğu düşünülmektedir. Ayrıca, yüksek sıcaklığın doğal taş pürüzlülük özelliklerine etkisi ile ilgili yapılan çalışmalarda sıcaklığın minerallerin genleşmesine neden olarak kayaçta mikro çatlak oluşumunu artırdığı ve mineral ayrılmasına yol açtığı belirtilmiştir [14,22].

\section{SONUÇLAR}

Yüksek sicaklığın doğal taşların petrografik, parlaklık ve pürüzlülük özelliklerine olan etkilerinin araştırıldığı çalışmanın sonuçlarından elde edilen verilere göre;

- Genel olarak, tüm numunelerde $700^{\circ} \mathrm{C}$ sıcaklıktan itibaren kalsit kristallerinde irileşme ve granoblastik dokuya geçiş görülmüştür. $\mathrm{Bu}$ olay numunelerde rekristalizasyon olayının başladığının göstergesidir. Ayrıca fosil izlerinde değişim ve fosil miktarında azalma olduğu gözlenmiştir. $800^{\circ} \mathrm{C}$ sicaklıkta ise tüm numunelerde fosil kavkıların büyük oranda yok olduğu ve kalsit kristalinde bozulma olduğu tespit edilmiştir. $900^{\circ} \mathrm{C}$ sicaklık sonrasında ise tüm numunelerde kalsit kristallerinin kaybolduğu ve karbonatlı yapının tamamen altere olduğu gözlenmiştir.

- Tüm numunelerin yüzey parlaklık değerlerinin sıcaklık artışıyla birlikte azaldığı ve bu azalışın özellikle $\quad 700^{\circ} \mathrm{C}$ sicaklıktan itibaren belirginleştiği gözlenmiştir. Bunun nedeni kalsit mineralinin yapısında bu sicaklıktan itibaren bozulmanın daha fazla gerçekleşmesidir. Ayrıca, numuneler arasında en düşük parlaklık değeri RV numunesine aittir. $\mathrm{Bu}$ numune kalsit minerali dışında mineral (demir) içermektedir. Demir minerali varlığının doğal taş numunelerinin parlaklık değerini azalttığı düşünülmektedir.
- Yüzey pürüzlülük ölçüm sonuçları incelendiğinde $700{ }^{\circ} \mathrm{C}$ sicaklıktan itibaren tüm numunelerde belirgin bir şekilde pürüzlülük artışı gözlenmiştir. Bunun nedeni, sıcaklıkla birlikte minerallerin genleşmeye uğraması ve dolayısıyla da numunelerde mikro çatlak oluşumunun artmasıdır.

\section{TEŞEKKÜR}

$\mathrm{Bu}$ çalışma. Van Yüzüncü Y1l Üniversitesi Bilimsel Araştırma Projeleri Koordinasyon Birimi tarafından FBA-2018-6808 nolu proje kapsamında gerçekleştirilmiştir.

\section{KAYNAKLAR}

1. Chakrabarti, B., Yates, T., Lewry, A., 1996. Effect of Fire Damage on Natural Stonework in Buildings. Construction and Building Materials, 10 (7), 539-544.

2. Dong, Z,. Sun, Q., Ye, J., Zhan, W., 2020. Changes in Color and Roughness of Red Sandstone at High Temperatures, Bulletin of Engineering Geology and the Environment. 79, 1959-1966.

3. Sanmartín, P., Siva, B., Prieto, B., 2011. Effect of Surface Finish on Roughness, Color and Gloss of Ornamental Granites, Journal of Materials in Civil Engineering, 1239-1248.

4. Zhang, W, Sun, Q., Zhu, S., Wang, B., 2017. Experimental Study on Mechanical and Porous Characteristics of Limestone Affected by High Temperature, Applied Thermal Engineering, 110, 356-362.

5. Kilıç, O., 2006. The Influence of High Temperatures on Limestone P Wave Velocity and Schmidt Hammer Strength, Technical note, International Journal of Rock Mechanics Mining Sciences, 43, 980-986.

6. Guo, Q., Su, H., Li, J., Yin, Q., Jing, H., Yu, L., 2020. An Experimental Study on the Fracture Behaviors of Marble Specimens Subjected to High Temperature Treatment, Engineering Fracture Mechanics, 225, 106862.

7. Sar1, D., Yavuz, H., 2001. Mermer Parlaklığının Nicel Tanımı. Türkiye III. 
Mermer Sempozyumu (MERSEM '2001) Bildiriler Kitabi 3-5 Mayis 2001/Afyon.

8. Kilıç, Ö., 2014. Application of Ultrasonic Velocity Measurement and Thermal Analysis for Determination of Limestone Quality, Physicial Problem of Mineral Processing 50, 525-533.

9. Ozguven, A., Ozcelik, Y., 2013. Investigation of Some Property Changes of Natural Building Stones Exposed to Fire and High Heat, Constr. Build. Mater. 38, 813-821.

10. Kilıç, O., 2006. Effects of Limestone Characteristics Properties of Calcination Temperature on Lime Quality, Asian Journal of Chemistry, 18(1), 655-666.

11. Sengun, N., 2014. Influence of Thermal Damage on The Physical and Mechanical Properties of Carbonate Rocks, Arab J Geosci., 5543-5551.

12. Kompanikova, Z., Heras, M.G., Michnova, J., Durmekova, T., Vlcko, J., 2014. Sandstone Alterations Triggered by Fire-Related Temperatures, Environ Earth Sci., 72, 2569-2581 DOI 10.1007/s12665-0143164

13. Biró, A., Hlavicka, V., Lubló, E., 2019. Effect of Fire-Related Temperatures on Natural Stones, Construction and Building Materials, 212, 92-101.

14. Vazquez, P., Acuña, M., Benavente, D., Gibeaux, S., Navarro, I., Heras, M.G., 2016. Evolution of Surface Properties Of Ornamental Granitoids Exposed To High Temperatures, Costruction and Building Materials 104 (1), 264-275.

15. Gómez, W.S.G., Quintana,. P., Pat, A.M., Avilés, F., Crespoa, J.M., Gil, J.J.A., 2015. Thermal Effects on the Physical Properties of Limestones from the Yucatan Peninsula. International Journal of Rock Mechanics and Mining Sciences, 75, 182-189.

16. Erdogan, M., 2000. Measurement of Polished Rock Surface Brightness by Image Analysis Method, Engineering Geology, 57, 65-72.

17. Heras, M.G., Vazquez, P., Carrizo, L., For,. R,. Alonso, F.J., 2010. Effects of High Temperatures in Building Granites: MicroCracking Patterns and Ultrasound Velocity
Attenuation, Geologica Balcanica, 39(1-2), 138.

18. Cevheroğlu, S., Dağ, A., Karakuş, A., 2018. Investigation of the Effects of Marble Material Properties on the Surface Quality, Advances in Materials Science and Engineering, 4, 1-7.

19. Gürcan, S., Goktan, R.M., Yıld1z, A., 2014. Effect of Mineralogical and Microstructural Properties on Surface Roughness and Gloss of Some Ornamental Marbles Subjected to Polishing Process, X-Ray Spectrometry, 43, 70-78.

20. Hajpál, M., 2006. Thermal Stresses. In Fracture and Failure of Natural Building Stones. Springer, Netherlands, 439-445.

21. Karaca, Z., 2012. Relationship Between The Mechanical Properties and The Surface Roughness of Marble, International Journal of Materials Research, 103 (5), 633-637.

22. Öcal, A.D., Dal, M., 2012. Doğal Taşlardaki Bozunmalar, Mimarlık Vakfi İktisadi İşletmesi, Müka Matbaasi.

23. Allison, R.J., Bristow, G.E., 1999. The Effects of Fire on Rock Weathering: Some Further Considerations of Laboratory Experimental Simulation, Earth Surface Processes and Landforms, 24(8), 707-713.

24. Goudie, A.S., Allison, R.J., McLaren, S.J., 1992. The Relations Between Modulus of Elasticity and Temperature in the Context of The Experimental Simulation of Rock Weathering by Fire, Earth Surface Processes and Landforms, 17, 605-615.

25. TS EN 12407, 2019. Doğal taşlar-Deney yöntemleri-Petrografik inceleme, Türk Standartları Enstitüsü, Ankara. 
